\title{
Temporal and spatial analysis of ozone concentrations in Europe based on timescale decomposition and a multi-clustering approach
}

Eirini Boleti et al.

Correspondence to: Christoph Hueglin (christoph.hueglin@empa.ch)

The copyright of individual parts of the supplement might differ from the CC BY 4.0 License. 


\section{Contents}

S1 Choice of number of clusters 2

S2 Assessment of clusters $\quad 3$

$\begin{array}{lr}\text { S3 Additional information on clusters } & 10\end{array}$

$\begin{array}{llr}5 & \text { S4 MDA8 and 4-MDA8 trends } & 14\end{array}$

S5 Sites with negative Sihlouette width $\quad 14$ 


\section{S1 Choice of number of clusters}

The analysis of the appropriate number of clusters is shown in Figs. S1 and S2. The sum of squared distance error within a cluster is plotted against the number of clusters. The number of clusters where the sum of squared distance error is mostly minimized is considered to be the most appropriate choice.
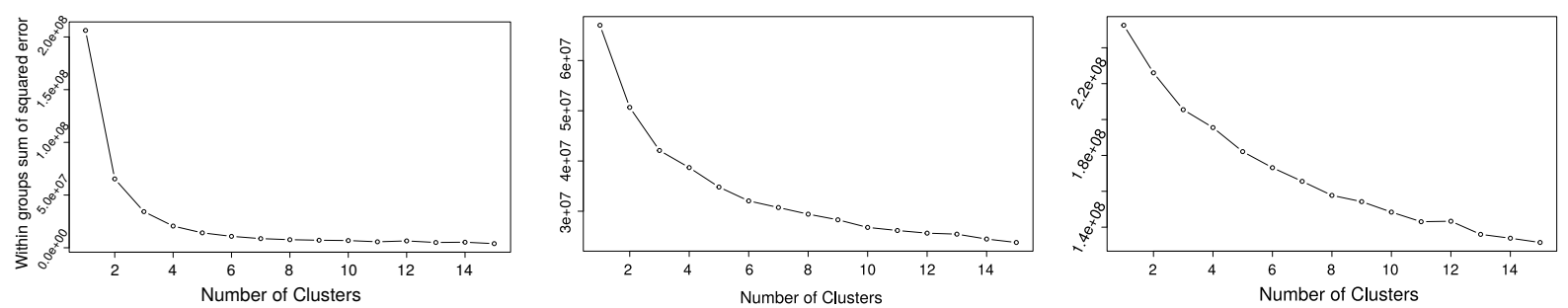

Figure S1. Sum of squared distance error within a cluster against number of clusters for daily mean $\mathrm{O}_{3} \mathrm{LT}(\mathrm{t}), \mathrm{S}(\mathrm{t})$ and $\mathrm{W}(\mathrm{t})$.
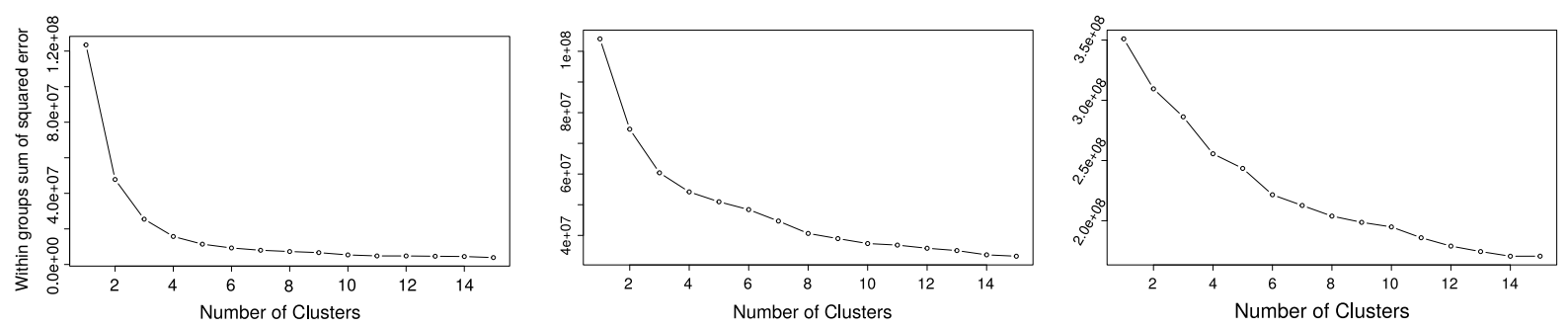

Figure S2. Same as Fig. S1 but for $\mathrm{MDA}_{8} \mathrm{O}_{3}$. 


\section{S2 Assessment of clusters}

Silhouette width $\left(\mathrm{S}_{w}\right)$ is considered a good metric to assess the goodness of a clustering. Positive Silhouette width values mean that objects within the cluster have high similarity while negative ones mean that the objects have low similarity with the rest of the objects in the cluster. Here, a $S_{w}$ is assigned to each member of the cluster (here each measurement site) to assess the

5 level of similarity in the cluster. It is defined as:

$S_{w}=\frac{b(i)-a(i)}{\max [a(i)-b(i)]}$

where $a(i)$ the average distance (dissimilarity) of $i$ with all other data points within the same cluster and $b(i)$ the lowest average distance of $i$ to all points in any other cluster, of which $i$ is not a member. Positive $S_{W}$ value for a specific site means that similarity to other sites in the cluster is high. A negative $\mathrm{S}_{w}$ indicates that a site is more similar to a site from another cluster than to its own cluster centroid, and is an indication of lower similarity to other sites in its own cluster.

$\mathrm{S}_{w}$ plots for daily mean $\mathrm{O}_{3}$ are shown in Figs. S3-S5 and for the MDA8 $\mathrm{O}_{3}$ in Figs. S6-S8. 
Silhouette plot of pam(x = data.matrix, $k=4$, metric = "euclidean")

$\mathrm{n}=291$

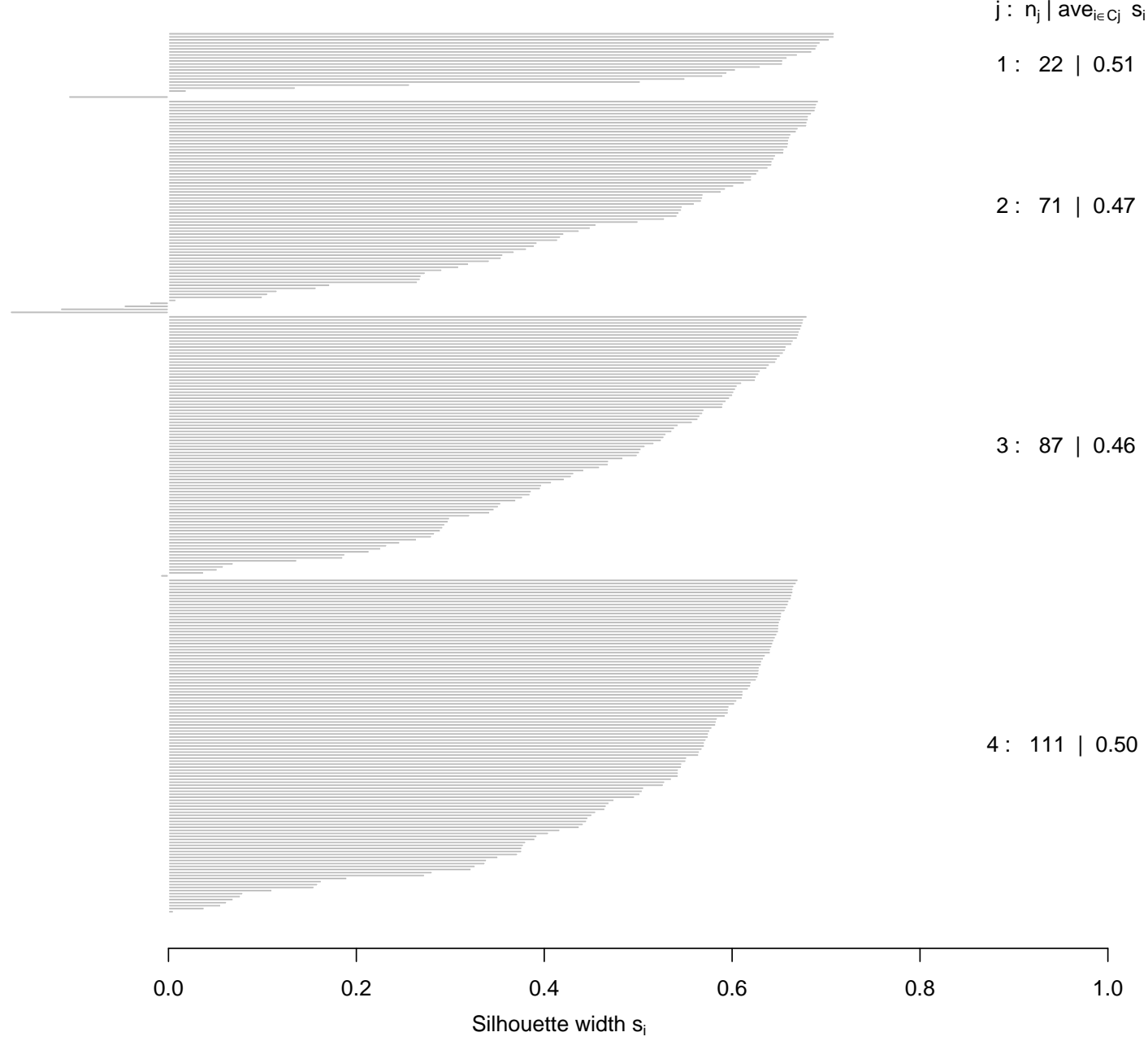

Average silhouette width : 0.48

Figure S3. Silhouette width plots for daily mean $\mathrm{O}_{3} \mathrm{LT}(\mathrm{t})$. The bars indicate the value of the $\mathrm{S}_{W}$ for a particular site within the respective cluster. For the majority of the sites the $\mathrm{S}_{W}$ is positive showing high similarity within the clusters. 
Silhouette plot of pam(x = data.matrix, $k=5$, metric = "euclidean") $\mathrm{n}=291$

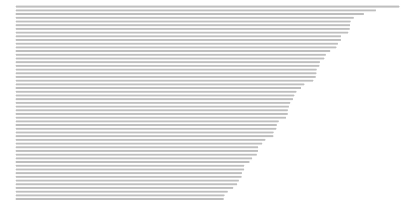

$1: 94 \mid 0.20$

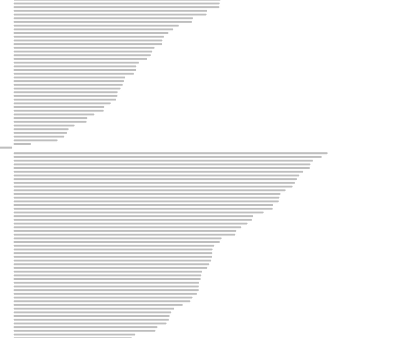

$2: 92 \mid 0.13$

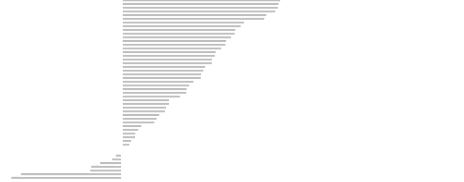

$3: 77 \mid 0.08$

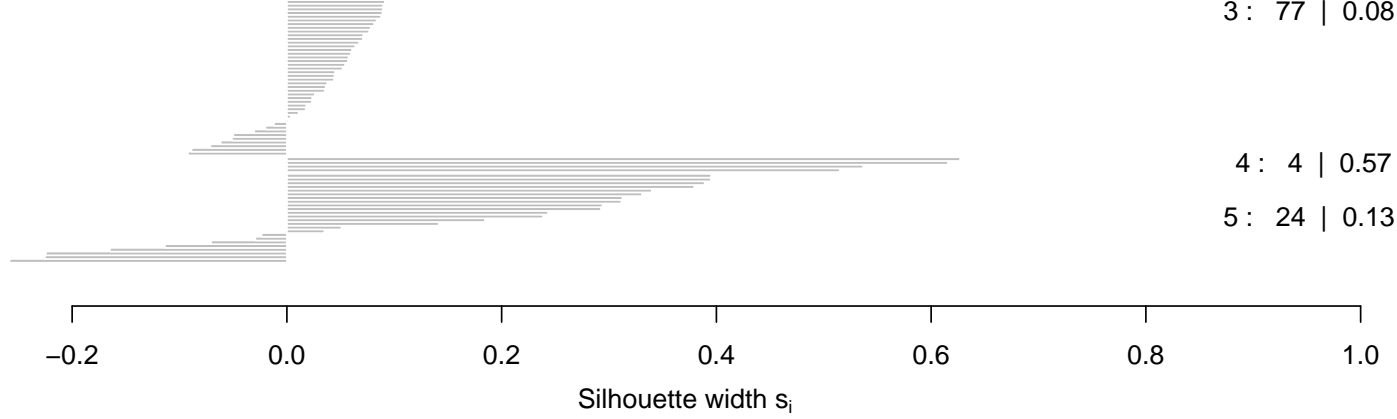

Average silhouette width : 0.14

Figure S4. Same as in Fig. S3 but for S(t). 
Silhouette plot of pam(x = data.matrix, $k=5$, metric = "euclidean")

$$
\mathrm{n}=291
$$

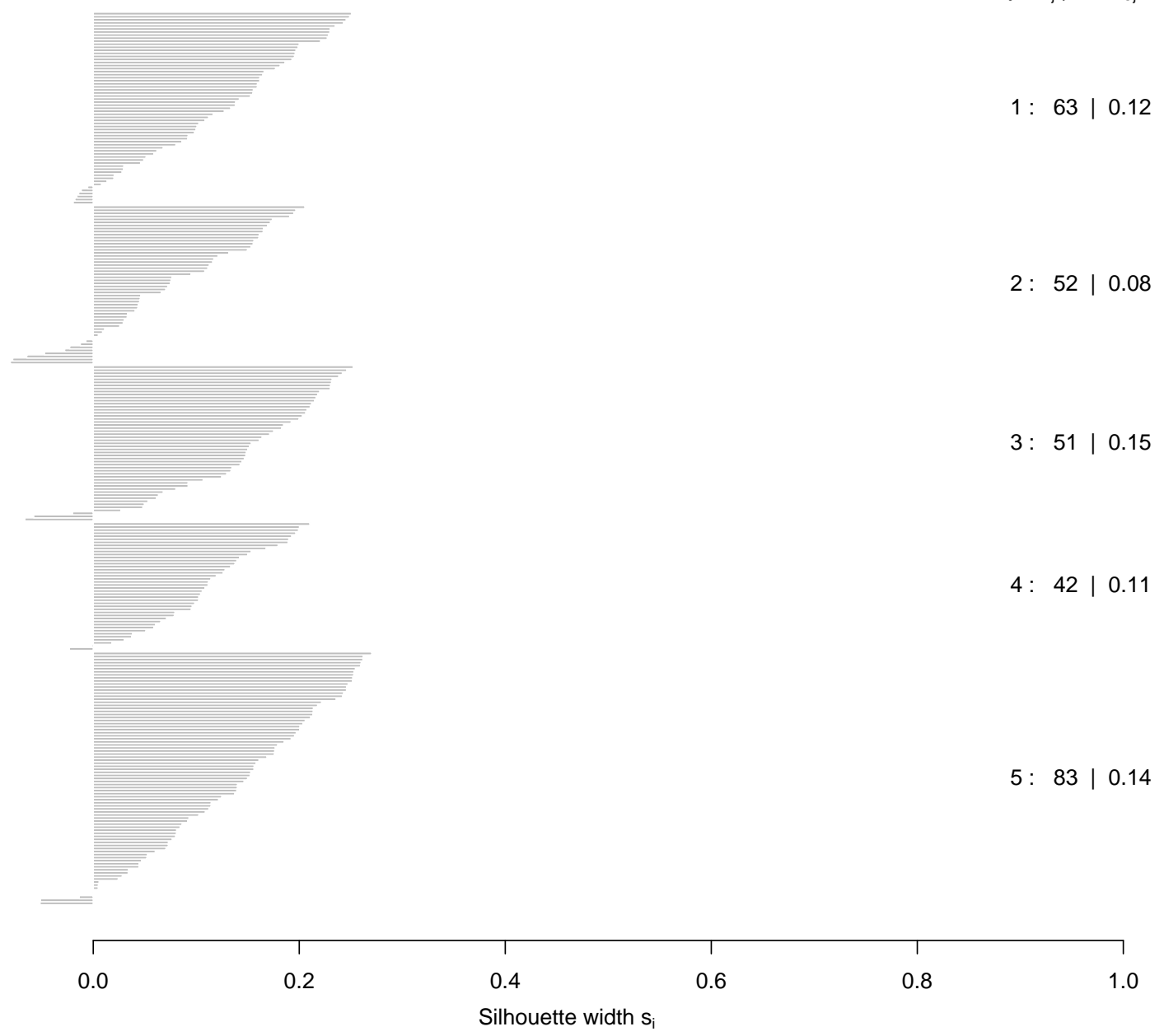

Average silhouette width : 0.12

Figure S5. Same as in Fig. S3 but for W(t). 
Silhouette plot of pam(x = data.matrix, $k=4$, metric = "euclidean") $\mathrm{n}=291$

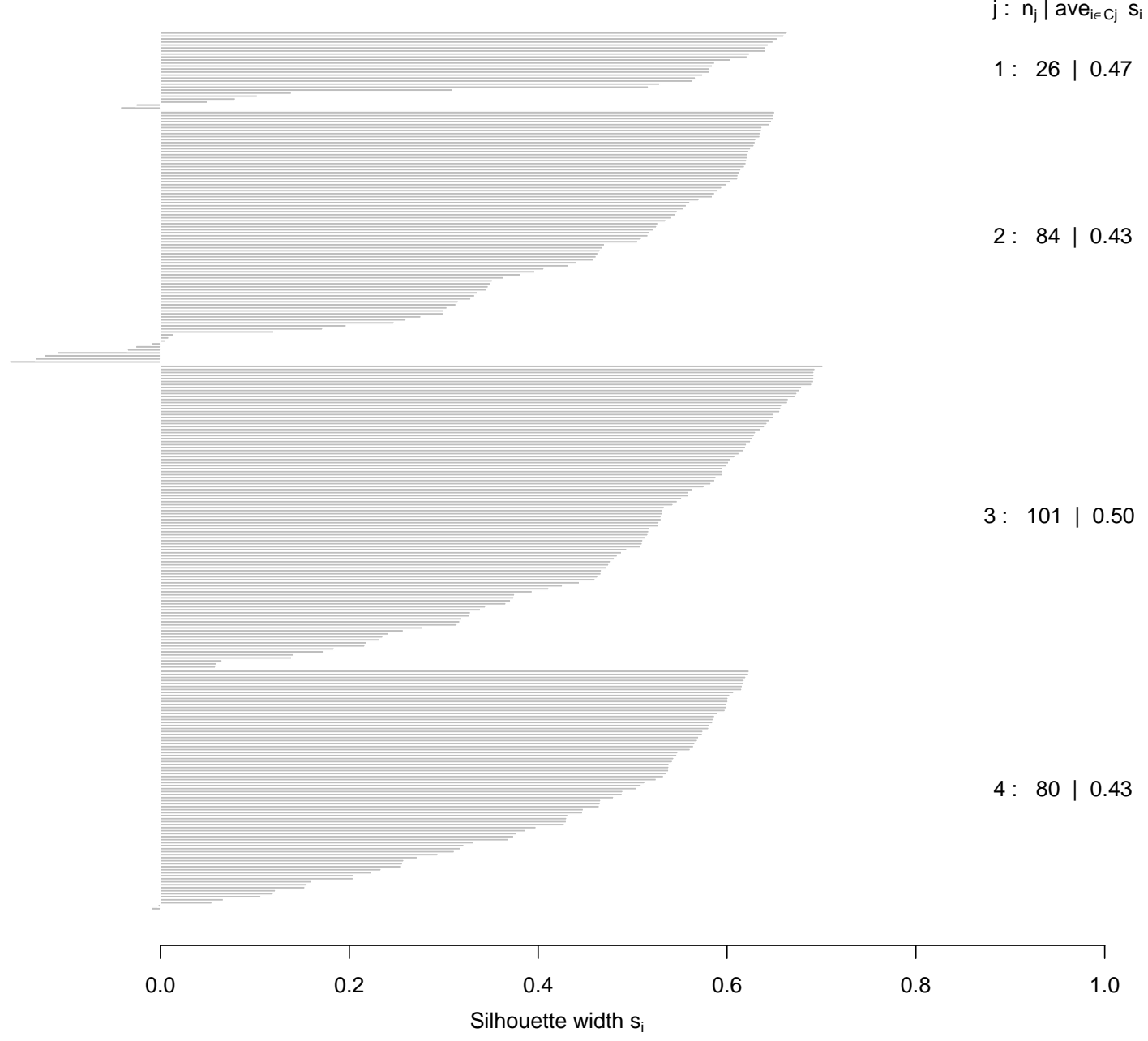

Average silhouette width : 0.46

Figure S6. Same as in Fig. S3 but for MDA8 LT(t). 
Silhouette plot of pam(x = data.matrix, $k=5$, metric = "euclidean") $\mathrm{n}=291$

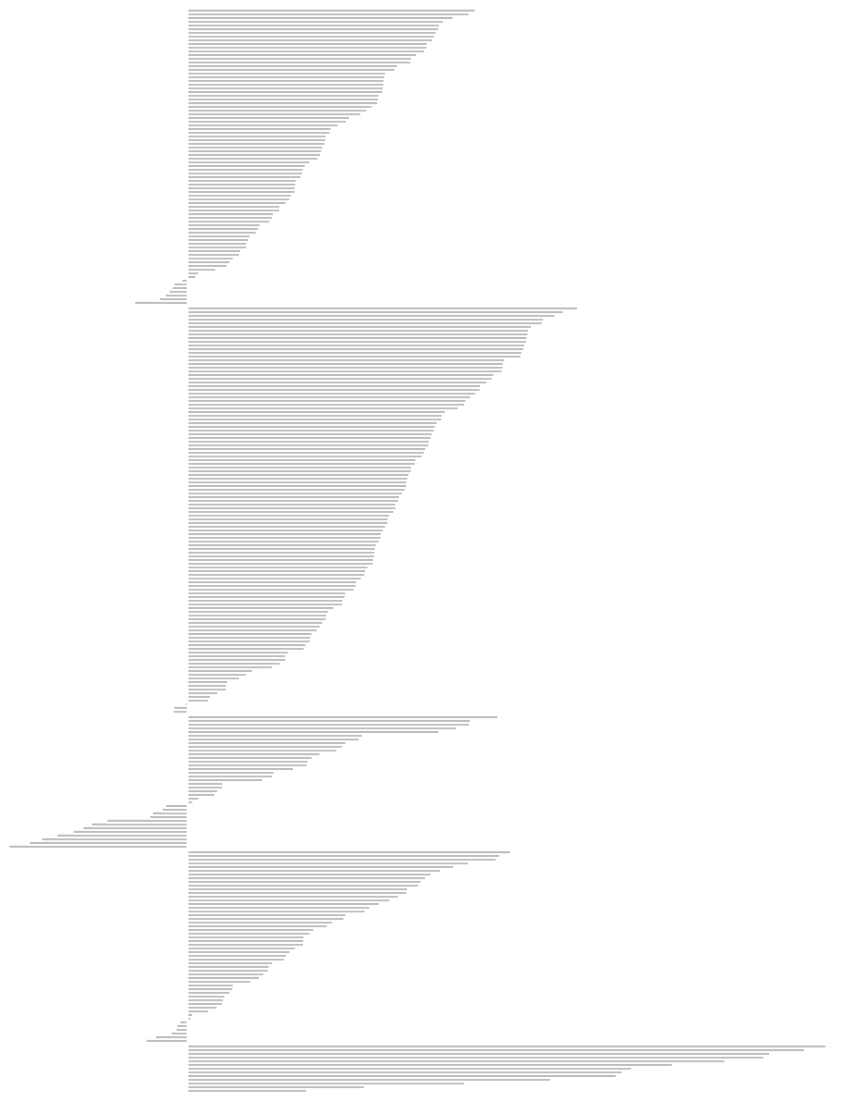

Silhouette width $\mathrm{s}_{\mathrm{i}}$

Average silhouette width : 0.14

Figure S7. Same as in Fig. S6 but for S(t). 
Silhouette plot of pam(x = data.matrix, $k=5$, metric = "euclidean")

$\mathrm{n}=291$

5 clusters $\mathrm{C}_{\mathrm{j}}$

$\mathrm{j}: \mathrm{n}_{\mathrm{j}} \mid \operatorname{ave}_{\mathrm{i} \in \mathrm{Cj}} \mathrm{s}_{\mathrm{i}}$

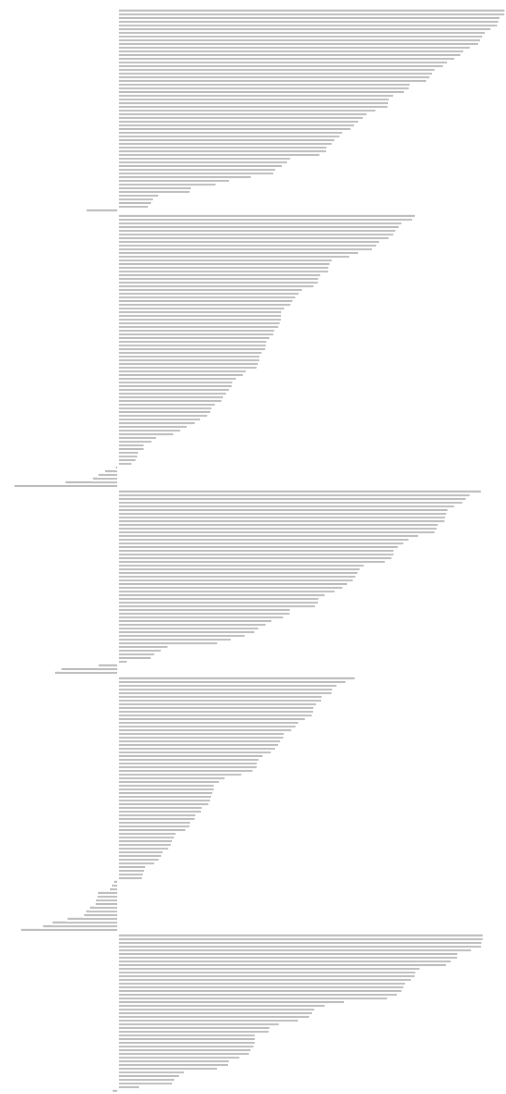

$1: 55 \mid 0.20$

$2: 74 \mid 0.11$

$3: 50 \mid 0.17$

$4: 69 \mid 0.07$

\begin{tabular}{|cccccc|}
\hline 0.0 & 0.2 & 0.4 & 0.6 & 1 & 1.0 \\
& & Silhouette width $\mathrm{s}_{\mathrm{i}}$ & & 0.8 & 1.8 \\
& & &
\end{tabular}

Average silhouette width : 0.14

Figure S8. Same as in Fig. S6 but for W(t). 


\section{S3 Additional information on clusters}

In this section we present more detailed information about the clusters extracted from the daily mean and MDA8 $\mathrm{O}_{3} \mathrm{LT}(\mathrm{t}), \mathrm{S}(\mathrm{t})$ and $\mathrm{W}(\mathrm{t})$ (Figures S9-S11). From the MDA8 $\mathrm{O}_{3} \mathrm{~S}(\mathrm{t})$ the following five clusters were identified: (1) "West" contains biggest part of France, Belgium and Spain, (2) "East" includes eastern and central Germany, eastern Austria and Czech Republic,

5 (3) "Central" covers most part of Switzerland, some sites in central Germany and eastern Austria, (4) "North" is the cluster covering sites in northern Germany (North Sea region) and Netherlands, (5) "Atlant-Infl" covers most of the UK, some sites in the West coast and Scandinavia influenced by background $\mathrm{O}_{3}$.

The five clusters obtained from the MDA8 $\mathrm{O}_{3} \mathrm{~W}(\mathrm{t})$ are the following: (1) "CentralEast" covers the region of eastern Austria, Czech Republic and Poland, (2) "Central" for central and southern Germany and northern Switzerland, (3) "NorthWest" is the cluster in northern France, Belgium and south UK (4) "SouthWest" in central and southern France, Spain and Italy, and (5) "NorthEast" includes the region of northern Germany, Netherlands and southern Scandinavia.

The following five clusters for daily mean $\mathrm{O}_{3} \mathrm{~W}(\mathrm{t})$ were obtained (Fig. S12): (1) "CentralEast" that includes eastern Austria, Czech Republic, Poland and stations in Baltic and northern Scandinavia, (2) "Central" with stations in south-western Germany and Switzerland, (3) "NorthWest" covering the UK, northern France and Belgium, (4) "SouthWest" with southern France and Spain, i.e. mostly the Mediterranean region, and (5) "NorthEast" for northern Germany, Netherlands and southern Scandinavia.
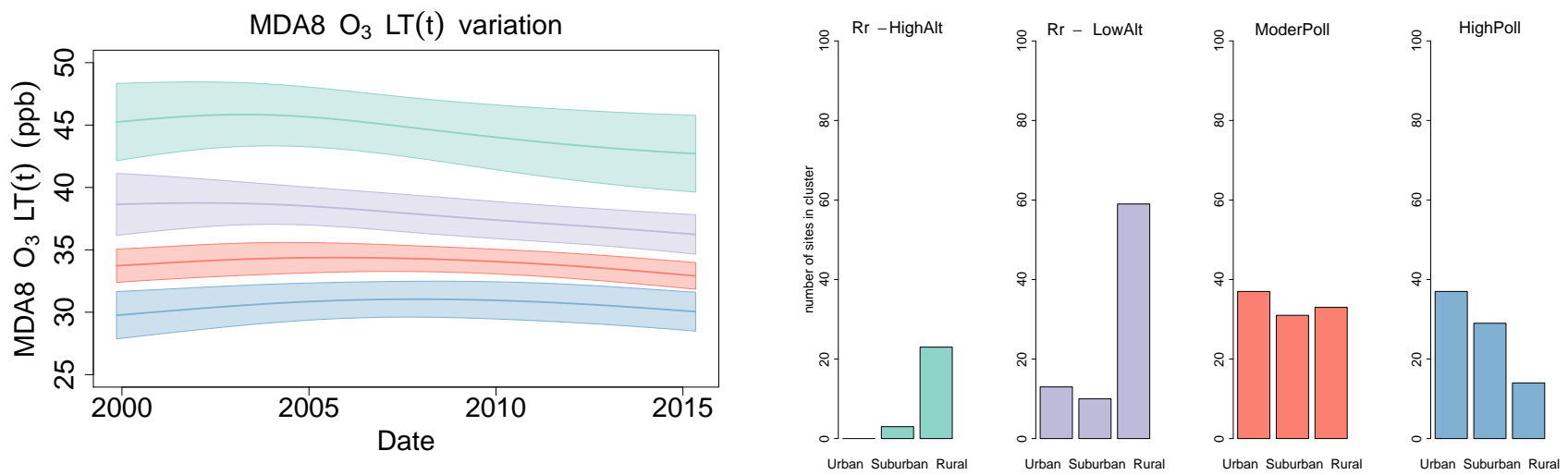

Figure S9. Clusters based on $\mathrm{MDA}_{8} \mathrm{O}_{3} \mathrm{LT}(\mathrm{t})$. Map indicating the sites that belong in each cluster and average LT(t) in each cluster with \pm the standard deviation of the sites that have $\mathrm{SW}>0$.

The daily mean and MDA8 $\mathrm{O}_{3} \mathrm{~W}(\mathrm{t})$-clustering resulted in clusters with a regional dependence, because it is mainly driven by short-term local meteorological conditions. Comparing the clustering based on $\mathrm{S}(\mathrm{t})$ and $\mathrm{W}(\mathrm{t})$, we conclude that both lead to a similar regional site classification. However, there are some differences: (a) the "Central" obtained by the daily mean $\mathrm{S}(\mathrm{t})$ clustering is divided in the $\mathrm{W}(\mathrm{t})$-clustering in two clusters the "Central" (south-western Germany and Switzerland without the Austrian sites of the S(t) cluster "Central") and the "CentralEast" (eastern Austria, Czech Republic, Poland and Baltic region, in $\mathrm{S}(\mathrm{t})$ those sites fall into the cluster "NorthEast"), (b) the "West" in the $\mathrm{S}(\mathrm{t})$-clusters appears in the W(t)-clusters as two separate clusters the "NorthWest" (UK, northern France and Belgium) and "SouthWest" (southern France and Spain), which in the $\mathrm{S}(\mathrm{t})$-clusters belong together in the "West" cluster. 


\section{MDA8 $\mathrm{O}_{3} \mathrm{~S}(\mathrm{t})$ Clusters}
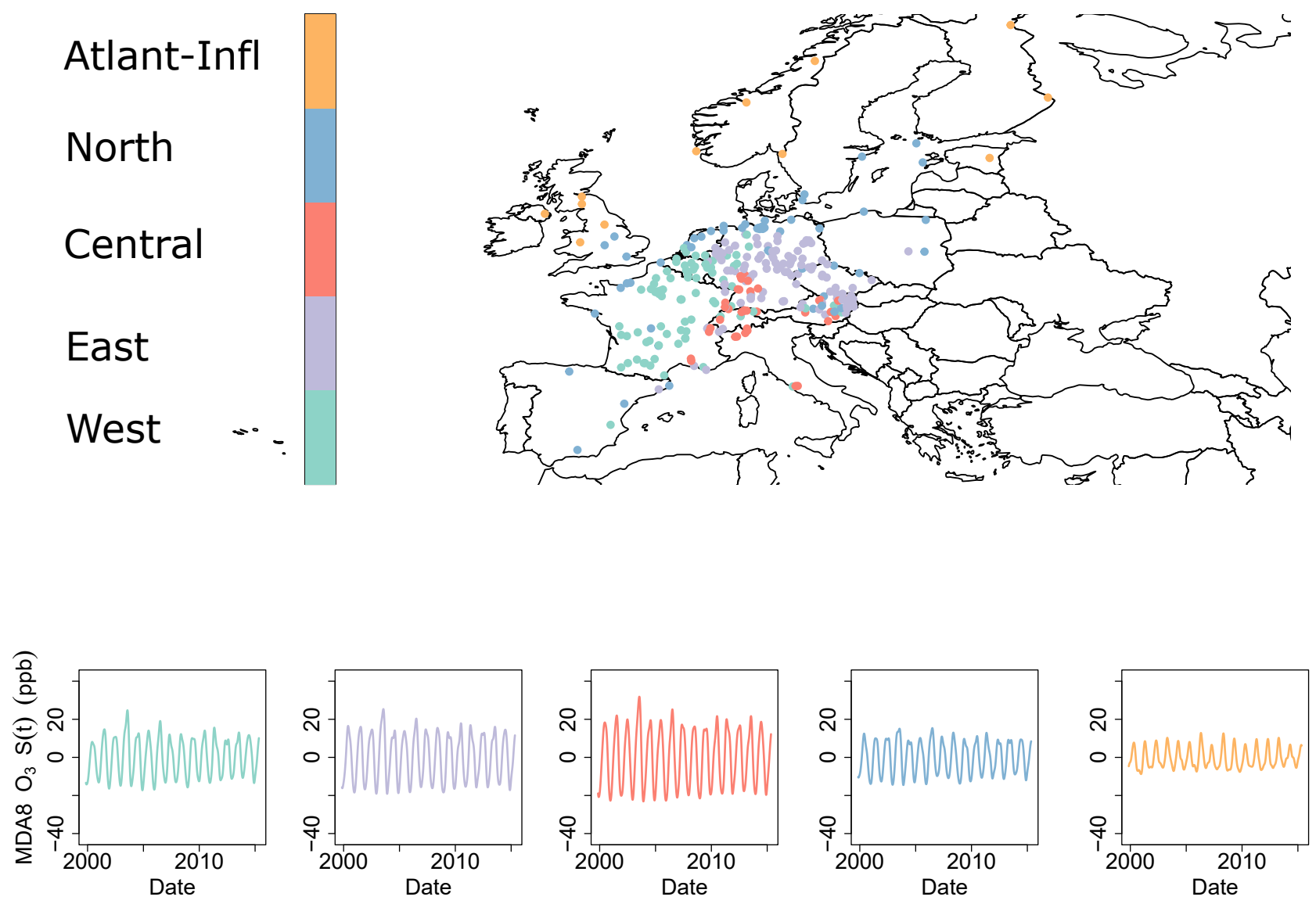

Figure S10. Clusters derived from $\mathrm{MDA}_{8} \mathrm{O}_{3} \mathrm{~S}(\mathrm{t})$. 


\section{MDA8 $\mathrm{O}_{3} \mathrm{~W}(\mathrm{t})$ Clusters}
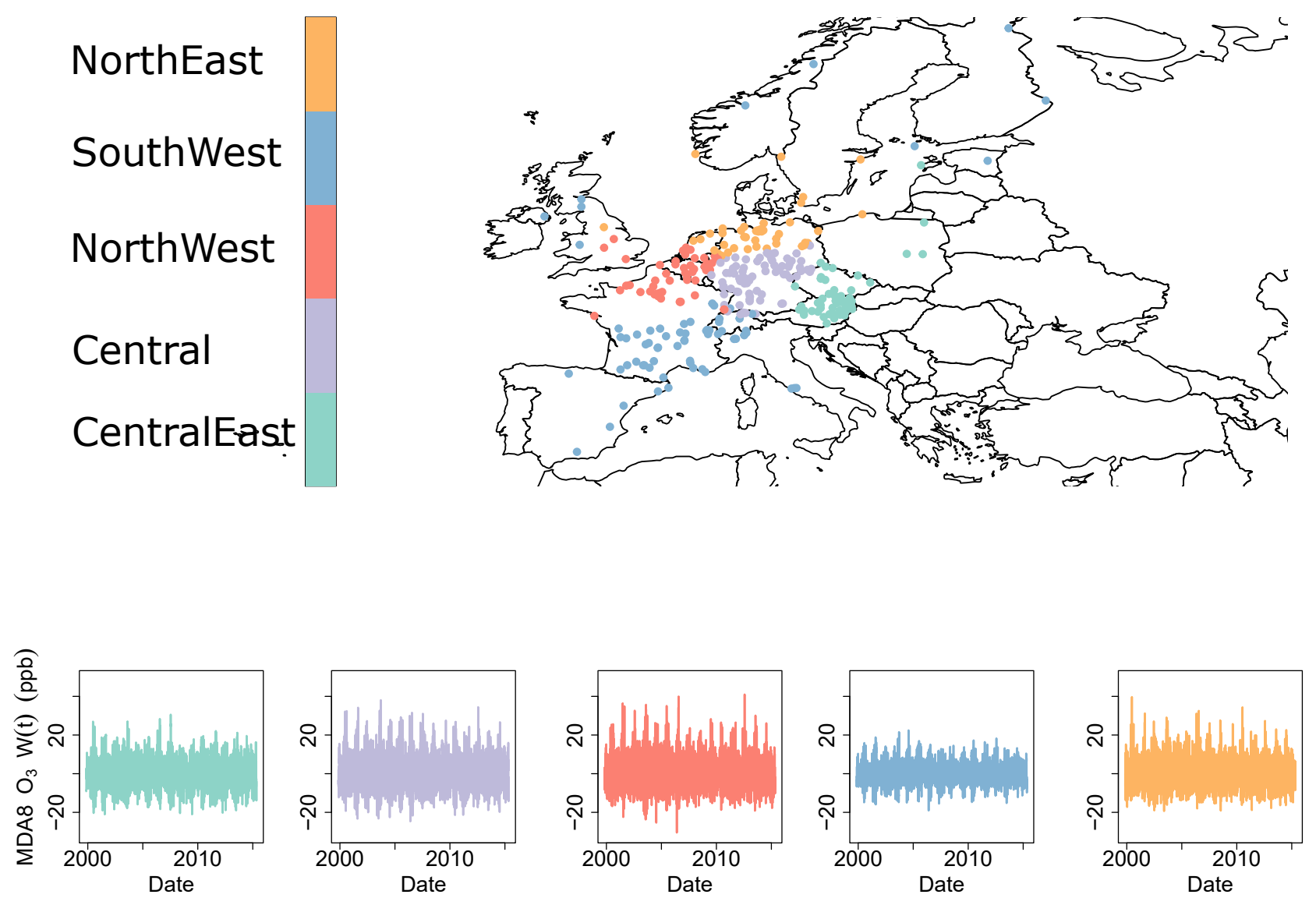

Figure S11. Clusters derived from $\mathrm{MDA}_{8} \mathrm{O}_{3} \mathrm{~W}(\mathrm{t})$. Map indicating the sites that belong in each cluster and average $\mathrm{W}(\mathrm{t})$ in each cluster of the sites that have $S_{W}>0$. 


\section{Daily mean $\mathrm{O}_{3} \mathrm{~W}(\mathrm{t})$ clusters}
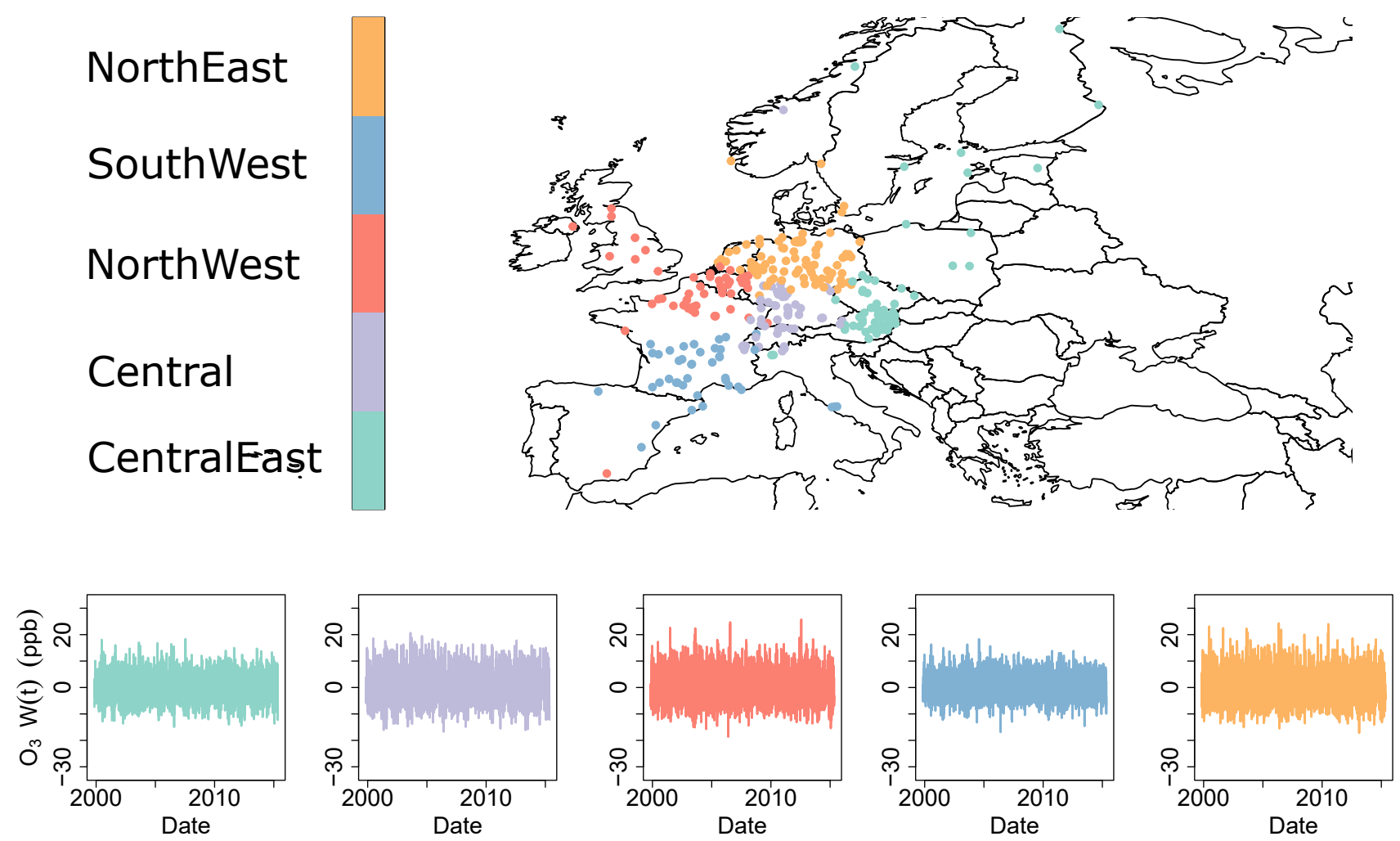

Figure S12. Clusters derived from daily mean $\mathrm{O}_{3} \mathrm{~W}(\mathrm{t})$.(a) Map indicating the sites that belong in each cluster and average $\mathrm{W}(\mathrm{t})$ in each cluster of the sites that have $S_{W}>0$. 


\section{S4 MDA8 and 4-MDA8 trends}

Trends of MDA8 $\mathrm{O}_{3}$ concentrations are negative in most sites. (Fig. S13). For the MDA8 $\mathrm{O}_{3}$ in $69 \%$ of all sites significant trends were found ( $80 \%$ among the significant trends were negative and $19 \%$ positive). The most pronounced decrease is observed in rural sites ("Rural-HighAlt" and "Rural-LowAlt"). The level off or small increase in the "HighPoll" stations can

5 be attributed to the smaller rate of reduction of VOCs ?, which resulted in reduced titration of $\mathrm{O}_{3}$ by NO. An additional explanation for the observed trend might be a change of chemical regimes , i.e. in the sensitivity of $\mathrm{O}_{3}$ production to $\mathrm{NO}_{x}$ and VOCs.

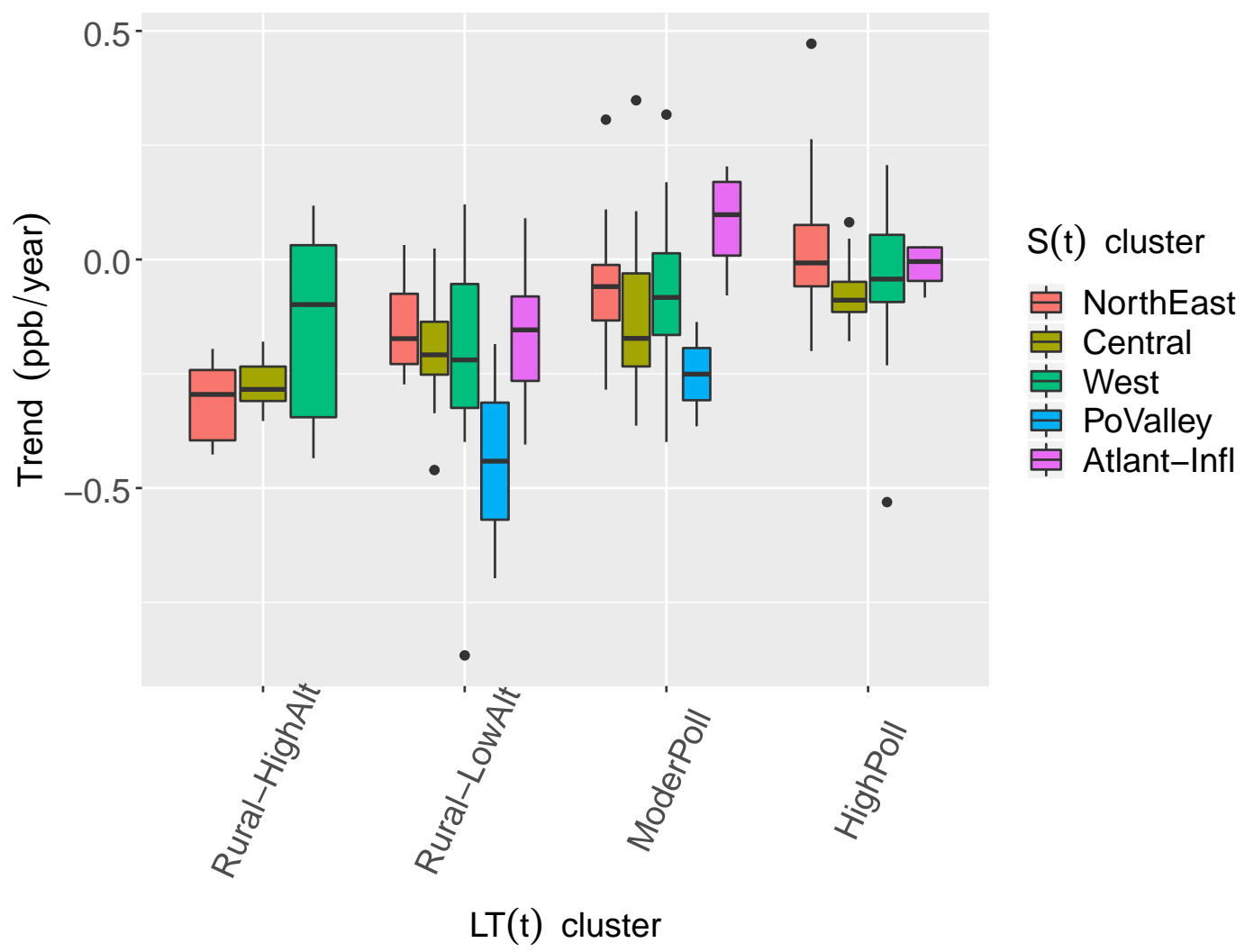

Figure S13. De-seasonalized MDA8 $\mathrm{O}_{3}$ trends for the daily mean $\mathrm{O}_{3} \mathrm{LT}(\mathrm{t})$ - and $\mathrm{S}(\mathrm{t})$-clusters.

Significant negative meteo-adjusted 4-MDA8 trends (Fig. S14) were observed in $47 \%$ of the sites, while without meteoadjustment significant negative trends were identified in only $18 \%$ of the sites. Overall, in $96 \%$ of all sites negative 4-MDA8 trends were calculated.

\section{S5 Sites with negative Sihlouette width}

Here, the sites with negative SW that were not considered in the discussion of the trends are presented. In the daily mean $\mathrm{O}_{3} \mathrm{LT}(\mathrm{t})$-clustering four sites with negative SW were identified (Fig. S15), in the S(t) 26 sites (Fig. S16) and in the W(t) 24 sites. This is probably due to some distinct differences in the LT(t), $\mathrm{S}(\mathrm{t})$ and $\mathrm{W}(\mathrm{t})$ compared to the rest sites in the cluster. By excluding these sites from the discussion of the long-term trends, we avoid strong deflections from the average behavior in the cluster. 


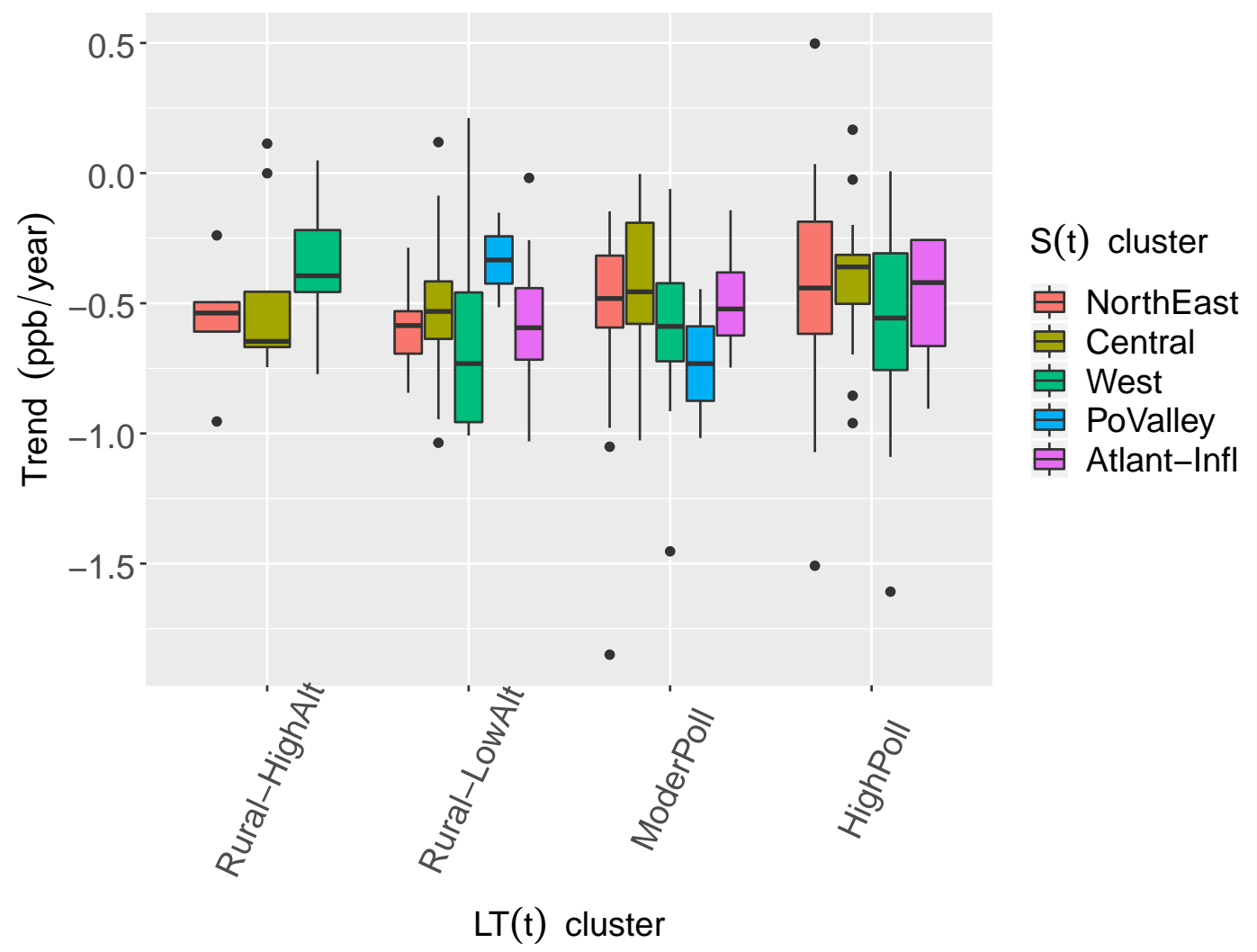

Figure S14. Trends of meteo-adjusted 4-MDA8 for the daily mean $\mathrm{O}_{3} \mathrm{LT}(\mathrm{t})$ - and $\mathrm{S}(\mathrm{t})$-clusters. 


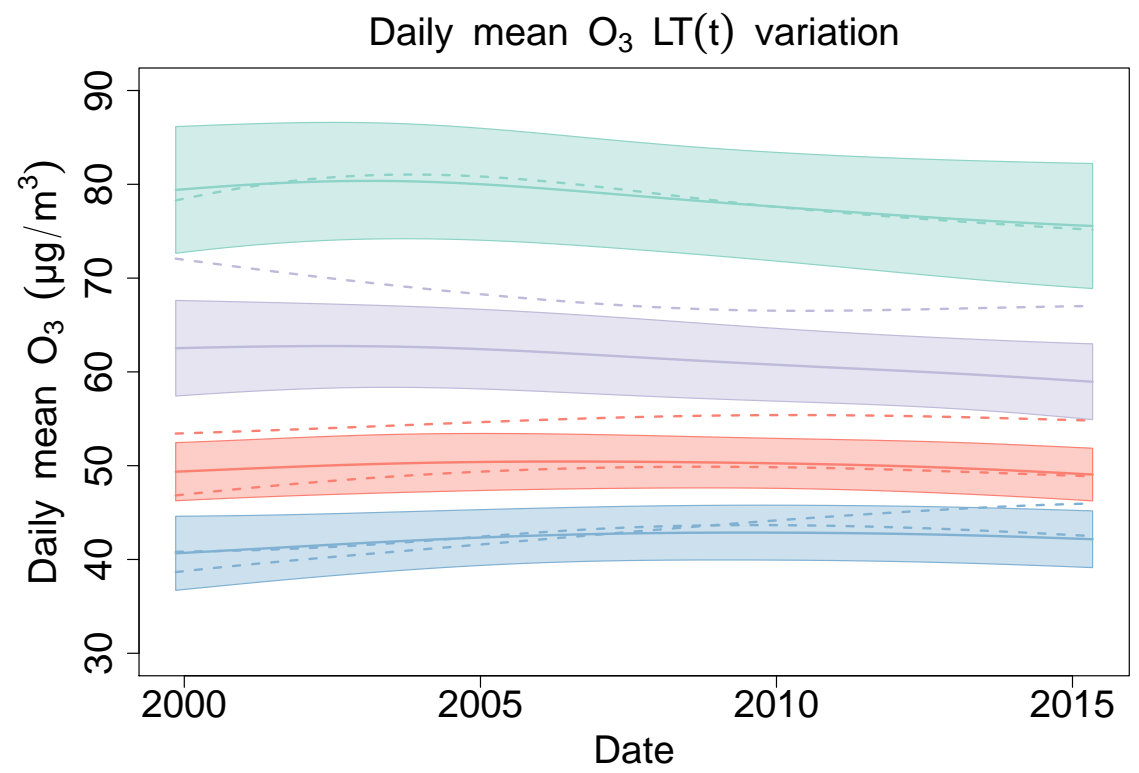

Figure S15. Sites with negative SW in the LT(t)-clustering, in comparison with the clusters average LT(t). Average LT(t) (lines) in each cluster with \pm the standard deviation (shaded area), and the $\mathrm{L}(\mathrm{t})$ of sites with negative $\mathrm{S}_{W}$ (dashed lines). 

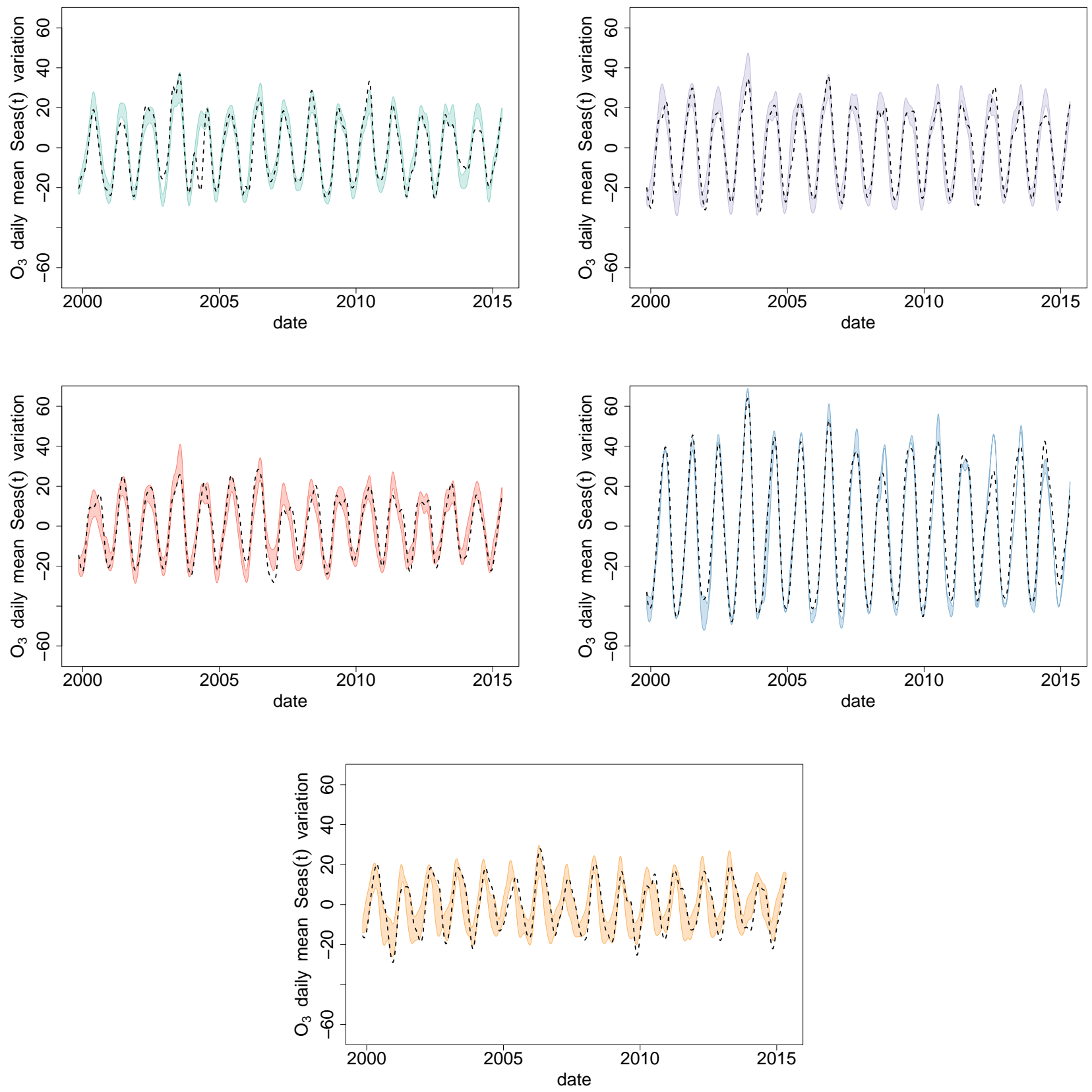

Figure S16. Example cases of sites with negative $\mathrm{SW}$ in the $\mathrm{S}(\mathrm{t})$-clustering (black dashed line) in comparison with the clusters average $\mathrm{S}(\mathrm{t})$ \pm the standard deviation (shaded area). 